\title{
DEVELOPMENT OF HEALTH-PROMOTING BEHAVIOUR OF A CHILD AS AN EDUCATIONAL GOAL IN FAMILIES OF HANDICAPPED MOTHERS WITH MENTAL HEALTH DISORDERS
}

\author{
Petra Hájková, \& Lea Květoňová \\ Charles Univ, Fac Edu, PedF UK (Czech Republic)
}

\begin{abstract}
The mental health of adult women is an important attribute of their motherhood. Weakening of mental health poses a threat to activities in the field of self-care and healthy development of their children. Even under these conditions of health disadvantage, women-mothers remain as the main mediators of health-promoting habits for their children, thus they become theirs first educators. The health literacy of these women also plays a role in this regard. For this reason, it is crucial to provide these women with sufficient special education that takes their individual needs into account.

This research project is focused on finding connections between the mental health disorder of mothers, their health literacy with manifestations in the field of health-promoting behaviour, and with the need for support in the relevant area of childcare by professionals and close family members.

The author will present an overview of research focused on this issue as well as her own proposal for a research solution, which received the support of the Charles University Grant Agency for the years 2021-2022.
\end{abstract}

Keywords: Mental health disorders, women with mental illness, health literacy, shared childcare, research.

\section{Introduction}

Within the European area, one in four persons gets affected by a mental health disorder (WHO, 2018). The statistics show that in the Czech Republic there are 53,212 women with a registered mental disorder spanning across the whole spectrum of diagnoses F00 - F99 which already qualifies as a disability. Out of this number, 25\% are women in their fertile years aged 20-39 (ÚZIS, 2018) who have custody of a child or more children. WHO study (2018) also indicates that the prevalence of women is similar worldwide. Cumulated roles in the society contribute to increasing the psychological pressure women are exposed to, and they affect their mental health. Women with SMI are, similarly to healthy women, expected to take over the primary responsibility for the developmental needs of their children even though they are themselves disadvantaged (Doucet et al., 2010, p. 298). However, serious mental illness (SMI) has the potential to affect the woman's functioning on a physical, social, professional as well as parental level (Saddock \& Saddock, 2007, p. 467). It can also influence the quality and quantity of her parental activities with regard to looking after the child's health (teaching him hygiene habits, healthy eating habits, sleep hygiene, mental hygiene, maintaining an exercise routine, injury prevention). In this context, the health literacy of women with SMI plays its role too, which means that there is an area involved that can be influenced by education also in adulthood or under the circumstances of SMI.

Our research team decided to investigate the links among the SMI of mothers, their motherly behaviour which encourages healthy habits in their children, and their need to share this care for children with a partner or other close family members. The goal of our research was to create an empirically grounded special educational intervention for women with mental health disorders provided within the integrated community care for people with SMI, which is - in the Czech Republic - just being developed.

Our research approach led us to a systematic review of domestic and foreign publications that provide empirical data for special educators focused on educational work towards women with mental health disorders during their motherhood. 


\section{Systematic review}

The systematic review, carried out by the research team in autumn 2020, was targeted on finding out a typical conceptualization of the problems listed in professional literature concerning women with SMI. We followed published results of research works carried out in years 2010-2020, which were indexed in three important bibliographic databases.

At first, relevant literature sources registered in the largest Czech bibliographic database Bibliographia medica Czechoslovaca (BMC) were chosen. This database includes 855 thousand specialised medical and health care documents of Czech as well as foreign origin (magazines, newspapers, monographs, collections). In addition to the medical field, the database expands to related social sciences.

Subsequently, sources from the international database CINAHL (Cumulative Index to Nursing \& Allied Health) which indexes 1,500 nursing and medical magazines as well as 5,500 journals from the whole world were chosen. CINAHL provides on its portal a full-text access to more than 500 magazines which also focus on health. The database indexes publications not only for researchers in the medical field but also for researchers from related social sciences. Therefore, it served as an important source for our systematic review too.

Further search was carried out in the MEDLINE database (Medical Literature Analysis and Retrieval System Online) at the US National Library of Medicine, which indexes international medical publications from research, clinical practise, administration, social politics and services aimed at public health and its protection. All above mentioned databases contain entries and full texts in multiple language versions. Only German and English, or as the case may be Czech and Slovak, versions were chosen for our purposes.

The selection included published results which met the following criteria:

1) They provided research data and outcomes concerning motherhood (parenthood) of women with mental health disorders (case studies, experimental research results, observations, qualitative studies including interviews, focus group, etc.);

2) They offered content concerning SMI in the context of family functioning and needs of women-mothers (functioning within the family and as a mother, or a combination of these key topics);

3) As to the conception of women's mental health, they went beyond a purely medical context.

The results were examined with regard to two interrelated research questions:

1. Are there any special needs of women with SMI during motherhood and child care?

2. Does SMI create any obstacles hindering care provision aimed at healthy development of the child?

\section{Research results}

Among the results published 2010 - 2020 we found in BMC 7 monographs and 16 specialised articles in Czech professional magazines, among others also 1 article published in Speciální pedagogika (Czech professional periodical for special educators). 3 found monographs didn't meet the 1st, the 2nd or the 3rd inclusive criterion. 7 specialised articles were eliminated due to duplicity and/or because of a purely medical focus (3rd inclusive criterion). 13 relevant publications of Czech provenience were examined as to represented topics and concepts of SMI.

Altogether, we identified 8 conceptual models of SMI depicted in professional literature published in the Czech Republic. Here you find them listed according to the frequency of their presence:

1. psychological model (12 occurrences) dealing with the developmental context of disorders and mental condition, self-concept, sense of self and self-perception of women with SMI in their role as a mother; 2. medical model ( 7 occurrences) focused on diagnosis and symptomatology of mental health disorders, their impact on the usage of health care services, medical costs linked to SMI, and results of psychiatric intervention as well as pharmacological treatment aimed at the well-being of women with SMI and their families; 3. sociological model (4 occurrences) highlighting the social consequences of chronical conditions in women, community service and supporting tools provided by the society; 4 . and 5 . Pedagogical/educational and training models (3 occurrences) following the educational impact a mother with SMI has on her child/children; 6. social work model (2 occurrences) focused on social services and intervention done by social workers in families of mothers with SMI; marginally also pathophysiological and socio-demographic model in which the authors concentrated on specific topics linked to mothers with SMI in families with children.

In the analysed publications, no attention was paid to the needs of mothers with SMI as to teaching the child heath promoting behaviours. The same applies to the chances of mothers with SMI to be involved in parenting activities in this respect. Being informed, health literacy and related responsibility of mothers with SMI or their need to share the care for a healthy development of their child 
in the family weren't mentioned in the followed sources at all. An exception represented two publications dedicated to motherhood of women with mental impairment written by a team of authors from Charles University (Strnadová, Bernoldová, Adamčíková, Klusáček, 2015; Strnadová, Mužáková, 2010).

Analysis of publications in English or German indexed in the databases CINAHL (Cumulative Index to Nursing \& Allied Health) and MEDLINE (Medical Literature Analysis and Retrieval System Online) brought a higher number of occurrences with clear relevance fulfilling our inclusive criteria.

Among the publications indexed in MEDLINE and CINAHL (Plus) in 2010-2020 could be found 50 magazine articles, out of which 33 met the inclusive criteria whereas 17 got eliminated because of not fulfilling the 2nd and 3rd criterion. Overall, 10 conceptual models could be identified in foreign sources, out of which were predominant:

1. psychological (14 occurrences); 2. social work models (9 occurrences); 3. medical (8 occurrences); 4. sociodemographic (7 occurrences), 5. educational and training models (7 occurrences); 6. socio-legal (6 occurrences); 7. pedagogical (6 occurrences), 8. epidemiological (4 occurrences); 9. socio-economic ( 2 occurrences) and 10. ethnological (1 occurrence), which was introducing the context of subcultures.

Foreign publications more often connect psychological topics to therapeutic, medical, educational themes as well as to informational support offered to women with SMI. They more frequently point out possible risks in regard to providing health promoting care for children in families where the mother has SMI. The thematization of these risks also happens with respect to accessible community services and family therapy. In German publications, publications from Great Britain, Finland, Australia, and the USA significant attention is paid to modern interventions and psycho-educational programs as well as rehabilitation programs for parenting couples or mothers with SMI and their children.

14 out of the found results directly focus on the needs of women-mothers in the fields of psychology, psycho-social help, practical help, help with developing a strategy in the family as well as concerning shared care for the child, or in the field of education and awareness. 27 found results contain support (online, educational, psycho-rehabilitation, etc.) programs verified by action or evaluation research. Significant tendencies to solve issues of women-mothers with SMI in an interdisciplinary manner could be found here. Besides, the conceptual models were intermingling much more. It can be stated that within the conceptual framework of foreign literature, the inclusive paradigm is predominant compared to the bio-medical paradigm. This is the case in all foreign sources which go beyond the medical context.

The review study has shown that it's necessary to widen the view researchers in the Czech Republic take on the motherhood of women with SMI. Besides, the instrumental content of support intervention offered in families of women-mothers with mental health disorders has to be broaden as well. It is needed to supply research argumentation in order to cover their individual and specific needs during motherhood and child care focused on the healthy development of the offspring. The persisting bio-medical paradigm in the conceptualisation of professional support given to these women is to be overcome. In addition to that, supporting educational and psycho-rehabilitation programs aimed at retaining functional parenting as well as family life of these women have to be developed. Apart from that, such programs have to give them opportunities of self-realization in their common social roles. Integrated services for mothers with SMI thematized in professional literature should cover not only their treatment and psychological or therapeutic service aimed at overcoming the consequences of SMI. They should also bring impulses in order to develop their parenting skills and practical family functioning in harmony with the inclusive paradigm in social sciences.

These findings inspired our team to conceive a research proposal named "The Needs of Women-Mothers with Chronical Mental Illness in the Area of Shared Childcare and Health Literacy" which received 100\% support of Charles University Grant Agency for 2021-2022.

\section{Research intent}

Our research intents to identify the needs of women with chronical mental illness with regard to the area of shared child care and to find out strategies these women intentionally use for ensuring the healthy development of their children.

The research will be conducted through semi-structured interviews with 22 women with chronical mental illness who have been having this condition since more than a year during their motherhood and care for a child (children) under 7 years of age. The control group will be constituted by 22 women-mothers without any diagnosed disorder in the area of mental health. These mothers will have children of the same age. The interviews with both groups of women will focus not only on needs during motherhood and child care but also on specific significance they (or their family members) attribute to mental health and health literacy. 
The study will be based on purposive sampling of women with chronic disease in the diagnosed spectrum F00-99 according to ICD-10 and on the control group of women without any diagnosed mental illness. The selection will be made on the basis of comparable demographic features of the two groups (age, family status, number of children up to 7 years of age, education).

We will make use of the following four technical elements which support the interviewing process in its function and fill the gaps in the data collection:

1. indicative questionnaire (for the collection of demographic data)

2. audio recording of the interview (dictating machine)

3. interview transcripts (MS Word, Excel)

4. postscripts

The indicative questionnaire can concentrate on biographical information about the participants: age, status, education, work position or disability level, diagnosis (F00-F99, with the exclusion of disorders due to alcohol addiction or addiction on any other substances), frequency of relapses, number of children in custody, etc. Audio recording the interview will ensure that all the statements are registered in an exact way. Subsequently, the recordings will be completely transferred to a text version according to transcription rules. All names and places will get changed in order to respect anonymity of research. The so-called postscripts will be added to the audio recording, that means field comments such as comments on the course of the interview, information about non-verbal and situational behaviour of participants or any other important circumstances of the interview. The interviews will undergo an analysis using software XLSTAT Basic+ for coding and data modelling. After that, the comparative method will be used to distinguish needs of women with SMI and without (in the area of health literacy and shared care for a child or children in their families).

The outputs will be confirmed by using members check and peer debriefing where partial conclusions will be given to several research participants for comments and assessment. Continuous assessment and commenting on the outcomes during "peer debriefing" (procedure review, methodology also with regard to outcomes in order to ensure validity) will be primarily carried out within the research team.

\section{Expected outcomes}

Identifying the needs of mothers with SMI in the area of care for the healthy development of their children in the context of shared care in the family will bring concrete impulses for specialised educational intervention based on proofs addressed at families in which mothers have SMI. Educational service for women with SMI can improve the relationships and wellbeing in the families, liberate them from fear and anxiety caused by insufficient family and parental functioning. In addition to this, it can contribute to their destigmatisation.

This paper was written thanks to GA UK (Charles University Grant Agency) which fully supported the project Needs of Women-Mothers with Chronic Mental Illness in the Area of Shared Child Care and Health Literacy (no. 251891, 2021-2022). The researcher is a doctoral student at the Faculty of Education, Charles University in Prague.

\section{References}

Doucet, S., A. et All. (2010). Contemporary paradigms for research related to women's mental health. Health Care for Women International, 31 (4), p.296-312, Retrieved March 31, 2021, from: http://dx.doi.org/10.1080/07399330903518509.

Institute of Health Information and Statistics of the Czech Republic. (2018). Psychiatrická péče 2017. Prague: IHIS CR. ISBN 978-80-7472-178-6.

Sadock, B., J., Sadock, V., A. (2007). Kaplan \& Sadock's synopsis of psychiatry: Behavioural science/clinical psychiatry (10th ed.). Philadelphia: Lippincott Williams \& Wilkins.

Strnadová, I., Bernoldová, J., Adamčíková, Z., Klusáček, J. (2015). Good Enough Support? Exploring the Attitudes, Knowledge and Experiences of Practitioners in Social Services and Child Welfare Working with Mothers with Intellectual Disability. JARID, 30 (3), p.563-572. ISSN: 1360-2322.

Strnadová, I., Mužáková, M. (2010). Mateřství žen s mentálním postižením. Speciální pedagogika, 20 (3), p.205-216. ISSN: $1211-2720$

World Health Organization. (2018). Culture and reform of mental health care in central and eastern Europe. Klecany: The WHO Regional Office for Europe, Czechia. ISBN 978-92-8905-307-5. 